\title{
ESPACIO PRIVADO, DIMENSIÓN PÚBLICA: HACIA UNA CARACTERIZACIÓN DEL CASINO EN LA ESPAÑA CONTEMPORÁNEA
}

por

\author{
RAFAEL VILLENA ESPINOSA \\ ÁNGEL LUIS LÓPEZ VILLAVERDE \\ Universidad de Castilla-La Mancha
}

RESUMEN: Las sociedades de recreo han sido la forma de sociabilidad más usual de la España contemporánea. No obstante, la abundancia de estas instituciones no siempre ba merecido el tratamiento que requeririan. El propósito de este trabajo se centra, pues, en delimitar el campo de estudio, of recer un estado de la cuestión que sirva para trazar las pautas metodológicas que deben alumbrar trabajos futuros y resaltar las variadas perspectivas de las sociedades recreativas. Con ello pretendemos contribuir a una mayor comprensión de la sociabilidad contemporánea y, cómo no, de la bistoria cotidiana de la burguesía española.

Palabras Clave: Casino. Círculo. España. Ocio. Siglos XIX y XX. Sociabilidad. Sociedades de recreo.

ABSTRACT: Leisure societies have been the most common form of sociability in modern Spain. However, the abundance of these institutions has not always generated the treatment they demand. The object of this article is therefore to define the field of study, and to assess the state of the scholarship to sketch the outline that future work should follow, and to emphasise the varied forms of recreational societies. The intention is to contribute to a greater understanding of modern sociability, and of course to the bistory of the daily life of the Spanish bourgeoisie.

KeY words: Casino. Club. Spain. Nineteenth century. Twentieth century. Sociability. Leisure Societies. 
Las sociedades de recreo han sido la forma de sociabilidad más usual de la España contemporánea. No obstante, la abundancia de estas instituciones no siempre ha merecido el tratamiento que requerirían, quedando, en palabras de José Manuel Cuenca Toribio, «ocultas incomprensiblemente hasta períodos recientes a la atención de los investigadores» ${ }^{1}$. En este sentido en particular, y en el de la historiografía del ocio en general, la española ha quedado rezagada, aunque no huérfana, respecto a la británica o la francesa.

El propósito de este trabajo se centra, pues, en delimitar el campo de estudio, ofrecer un estado de la cuestión que sirva para trazar las pautas metodológicas que deben alumbrar trabajos futuros y resaltar las variadas perspectivas de las sociedades recreativas. Con ello pretendemos contribuir a una mayor comprensión de la sociabilidad contemporánea y, 'cómo no, de la historia cotidiana de la burguesía española.

\section{CASINO Y CÍRCULO: DIVERSIDAD DE NOMBRES PARA LAS SOCIEDADES DE RECREO}

La primera dificultad con que nos encontramos es su propia definición ${ }^{2}$. Reservado el concepto de ateneo para las instituciones con un mayor peso de la instrucción y la cultura, se suele usar la doble acepción de casino o de círculo para calificar las sociedades orientadas hacia las actividades recreativas, aunque no ignorasen las culturales ${ }^{3}$.

En cualquier caso, no se trata de una novedad española, sino la traducción de una modalidad que se empezaba a extender por la Europa posrevolucionaria y cuyas raíces eran incluso anteriores. El vocablo casino es de origen italiano, aplicado como diminutivo a las pequeñas construcciones de campo o de solaz que desde el siglo XVI permitían pasar a sus propietarios y sus invitados temporadas de descanso. Del casino renacentista, de carácter privado, se pasa al casino público, club, círculo o ateneo durante la Ilustración, concibiéndose entonces como centro de reunión de làs personas ilustradas 4 . Posteriormente, adopta el significado actual - perdiendo su relación con la naturaleza y conservando su aspecto público ochocentista- para convertirse en sinónimo de juego y ocio desde principios del XIX, con una clara vinculación social burguesa.

\footnotetext{
1 Cuenca Toribio, José Manuel: Prólogo al libro de Alcalá Ortiz, Enrique: El casino de Priego y otras sociedades recreativas (1848-1998), Priego, 2001, vol. 1.

2 Para el significado y evolución de las principales denominaciones empleadas por las asociaciones españolas contemporáneas, remitimos a nuestro trabajo, GEAS: España en sociedad. Las asociaciones a finales del siglo XIX, Cuenca, Ediciones de la Universidad de Castilla-La Mancha, 1998, pp. 33-59.

3 GUEREÑA, Jean-Louis: «La sociabilidad en la España contemporánea», en SÁNCHEZ SÁNCHEZ, Isidro y VILLENA ESPINOSA, Rafael: Sociabilidad fin de siglo: espacios asociativos en torno a 1898, Cuenca, Ediciones de la Universidad de Castilla-La Mancha, 1999, p. 32.

4 PÉREZ ROJAS, Javier: Casinos de la región murciana. Un estudio preliminar (1850-1920), Valencia, Colegio Oficial de Arquitectos de Valencia y Murcia, 1980, p. 12. 
Sobre su distinta terminología, la palabra casino se acabará convirtiendo en una forma más genuinamente castellana que otros neologismos como club (palabra inglesa que designaba los lugares donde se practicaba el juego y se organizaban bailes y fiestas) o círculo (de origen alemán, pasa a España a través de los franceses, pero hace referencia también a todo tipo de reunión, ambiente o sector social), y aceptada en mayor medida por carecer de intencionalidad política. Ahora bien, círculo y casino devinieron en vocablos sinónimos, aplicados a las sociedades de recreo que se extendieron por España para dar cobertura formal y reglada a lo que; con frecuencia, ya era un hábito de reunión. Por ejemplo, el Casino de Tolosa quedó inscrito en el Registro de asociaciones como "Círculo Recreativo Casino de Tolosa», prueba de la sinonimia entre ambos términos ${ }^{5}$ Y el Casino abulense tuvo en sus orígenes una múltiple denominación, como «centro", "círculo de recreo" y "casino" hasta que prevaleció la de «casino abulense» ${ }^{6}$.

De la triple tipología que Navascués Palacio realiza para el casino - el privado, semejante a un club inglés, el café público italiano y el marítimo, cosmopolita y veraniego, de influjo francés - ${ }^{7}$, el español sería, a juicio de Guimerá, mezcla del club inglés y el café italiano ${ }^{8}$, quedando como una excepción el marítimo, limitado sólo a San Sebastián.

Pues bien, el casino no sólo se convirtió en una significativa forma de asociación, sino también en un espacio idóneo para el desenvolvimiento de la sociabilidad informal, al albergar un lugar de encuentro, discusión e intercambio de ideas, y, sobre todo, solaz de sus socios. Eran, por un lado, lugares privados para hombres, concebidos como asociaciones sexistas y clasistas, pero a la vez, significaban un avance en el asociacionismo laico que - en el contexto del creciente industrialismo europeo- participaban de la aparición de sociedades anónimas sin ánimo de lucro nutridas por la nueva burguesía?.

Escenario privilegiado de la vida cotidiana local, primeramente de sus élites, no debe extrañar que haya tenido un notable tratamiento en la literatura española como "centro de interés» por el que pasan sus personajes, bien para facilitar el encuadre del desarrollo narrativo, bien para criticar su inactividad,

\footnotetext{
5 Hoyo Simón, José Félix del: Casino de Tolosa, 1885-1985, Tolosa, Itxaropena, 1986, p. 7.

6 FERnÁNDEZ HERnÁNDEZ, Maximiliano: Casino abulense: un siglo de bistoria y encuentros (1897-1997), Ávila, Imprenta C. del Diario de Ávila, 1997.

7 NAVASCuÉs Palacio, Pedro: «El casino de Madrid y la arquitectura de su tiempo», en Tres conferencias de Arquitectura, Madrid, 1978.

8 Guimerá Ravina, Agustín y Darías PrínCiPe, Alberto: El casino de Tenerife (1840-1990), Santa Cruz de Tenerife, Casino de Tenerife, 1992, p. 27.

9 Ver, entre otros, VERA BOTI, Alfredo: El casino de Murcia: notas para bistoria de arquitectura ecléctica, Murcia, Colegio Oficial de Arquitectos de Murcia, 1991, p. 47.
}

Hispania, LXIII/2, núm. 214 (2003) 443-466 
ociosidad y mediocridad vital ${ }^{10}$. Así lo hacen, por ejemplo, Galdós en los Episodios Nacionales, Clarín en su Regenta o Juan Valera en Pepita Jiménez.

En los agitados años del Sexenio democrático, Galdós ubica así una escena como la que sigue:

«[...] Designado el día de mi venganza me alcé las botas de tacón más alto que en aquellas décadas poseía, cogí un roten nudoso que parecía la maza de Hércules y me fui derecho al Casino Moderado de la calle de Atocha, donde esperaba medir mi fiereza con la barbarie soez del tío más tío del mundo. Pronto comprendí que iba mal encaminado, porque al Círculo de la calle de Atocha no concurrían más que moderadotes de ropas limpias y elevada representación pública, como el señor Carramolino, el señor Moyano, el señor Collantes, el conde de Cheste y otros tales. Mejor orientado, me dirigí a un casinejo de reciente fundación, abierto en la calle de Jacometrezo con el mote de «Círculo Popular» no sé si «conservador» o «alfonsino», y apenas entré en la oscura, deslucida y puerca antesala, ó la voz del cernícalo graznando en estridente disputa con otros pajarracos de la fauna reaccionaria. Con un mozo que pasaba llevando servicio de café en abolladas cafeteras, mandé recado a mi enemigo»11.

Por su parte, Clarín traza magistralmente las relaciones entre el casino y la ciudad, y es el lugar a través del cual se muestra la mentalidad de sus ciudadanos, sus esperanzas y sus miserias ${ }^{12}$. Como recoge Pérez Rojas, "en el casino D. Álvaro cortejaba a la Regenta, y desde una ventana entreabierta, en un piso alto del casino, D. Víctor Quintanar observa a su esposa penitente en la procesión de Semana Santa» ${ }^{13}$.

Finalmente, Juan Valera pone en boca del protagonista de su novela, Luis de Vargas, una descripción del casino en la que se sintetizan algunos de sus rasgos más claramente definitorios:

«El casino es aquí mera diversión nocturna, si no de todas las horas del día. Desde las once de la mañana está lleno de gente que charla, que lee por encima de algún periódico para saber las noticias, y que juega al tresillo. Personas que hay que se pasan diez o doce horas al día jugando a dicho juego. En fin, hay aquí una holganza tan encantadora, que más no puede ser. Las diversiones son muchas, a fin de entretener dicha holganza. Además del tresillo se arma la timbirimba con frecuencia, y se juega al monte. Las damas, el ajedrez y el dominó no se descuidan. Y, por último, hay una pasión decidida por las riñas de gallos $[\ldots]{ }^{14}$.

10 Ver DíAZ PlAJA, Guillermo: «España en sus espejos. Los casinos», La Estafeta literaria, Madrid, $n^{\circ}$ 607, 1977, pp. 22-23, y PÉrEZ ROJAS, Javier: Casinos de la región murciana, op. cit., pp. 23-24.

11 PÉrez GAldós, Benito: Episodios Nacionales, n 43: Amadeo I, Madrid, Alianza Ed., 1987, p. 29.

12 Una descripción minuciosa del Casino de Oviedo en Clarín: La Regenta, ed. de SOBEjano, Gonzalo, Madrid, Clásicos Castalia, 1981, pp. 249-266.

13 PÉREz ROJAS, Javier: Casinos de la región murciana, op. cit., p. 24.

14 Valera, Juan: Pepita Jiménez, ed. de García Moreno, L., Madrid, 1988, pp. 100-101. 


\section{EL TRATAMIENTO HISTORIOGRÁFICO}

En la aún incipiente historiografía del ocio española, representan una proporción considerable las obras excesivamente localistas, que no se despegan del nivel puramente descriptivo y se limitan a relatar pormenorizada, cronológica y acríticamente las anécdotas y las «glorias» de la institución, aunque, al menos, suelen aportar una interesante documentación ${ }^{15}$. Lamentablemente, una década después de su publicación, sigue siendo válida la afirmación de Guimerá en el sentido de que «los mejores estudios de casinos han sido llevados a cabo por historiadores del arte», pues no ha concitado una excesiva atención de los contemporaneístas ${ }^{16}$. Eso no significa que no existan ejemplos pioneros y brillantes que además han tenido continuidad en los últimos años ${ }^{17}$.

Los estudios más destacables son aquellos capaces de imbricar la evolución del casino en la vida local y nacional, ofreciendo, a la vez, una metodología e interpretación novedosa. Entre los publicados en la década de los ochenta destacan el libro ya clásico de Pérez Rojas sobre los casinos murcianos, el pionero artículo de Pere Solà sobre los inicios del Casino de Llagostera o el de Guereña para la sociabilidad popular asturiana, que han tenido una feliz continuación en algunas monografías más recientes sobre el de Tenerife y los casinos republicanos catalanes.

Aunque centrado en los aspectos arquitectónicos, el libro de Pérez Rojas abandona cualquier perspectiva puramente localista para ofrecer una excelente panorámica de la historia y evolución de los casinos españoles y, partiendo de los ejemplos murcianos (Murcia, Cartagena, Lorca y Águilas, sobre todo), se adentra en la proyección externa del casino y en el simbolismo decorativo. Por su parte, el libro sobre el Casino de Tenerife, escrito por un historiador del C.S.I.C. y un profesor de historia del arte, introduce una novedad metodológica importante al analizar el casino desde varias perspectivas, esto es, como institución, empresa, sociedad de recreo privada, vida pública y espacio arquitectónico y urbanístico ${ }^{18}$.

15 Monografías localistas y sin mucho interés hay varias, pero valgan los casos siguientes de ejemplo. Lo anecdótico distribuido por períodos presidenciales es el eje del libro de GUIRAO LÓPEZ DE NAVAS, José: El casino de Murcia, 1847-1994, Murcia, Casino de Murcia-Asociación de la Prensa, 1994, 426 p. Incluso la autojustificación de un mandato presidencial es el motivo que llevó a la publicación del libro sobre el casino segoviano a CUESTA JORGE, Luis: Mis recuerdos de la recuperación y transformación del casino, Segovia 1976-1980, Segovia, 1999. De mayor interés, aunque sin dar el salto de calidad para considerarla una aportación destacable, es la de MARTín DE MARCO, José Antonio: El Casino y el Círculo de la Amistad-Numancia, 1848-1992, Soria, Diputación Provincial de Soria, 1992, 461 p.

16 Guimerá Ravina, Agustín y Darías PRÍNCIPE, Alberto: El casino de Tenerife, op. cit.

17 Entre los estudios más pioneros podemos destacar el de MONTERO ALONSO, José: El casino de Madrid, Madrid, Instituto de Estudios Madrileños, 1973, también el de OrOzCo AcuAvivA, Antonio: 130 años de la fundación del Casino Gaditano (27/X/1844-27/X/1974). Historia chica de un casino grande, Cádiz, 1975.

18 Respectivamente, PÉrez Rojas, Javier: Casinos de la región murciana, op. cit.; SOLÁ, Pere: «Instrucció i esbarjo a un cassino de comarques: l'arrencada del cassino Llagosterenc (1891-1903)», 
$Y$, aunque con un matiz diferente, también habría que englobar en este apartado el libro sobre el madrileño Círculo de bellas artes ${ }^{19}$. Esta institución, nacida en 1880 con una finalidad artística y cultural, derivó en efecto hacia actividades de corte recreativo y de holganza, de manera que tuvo también un cierto parecido a los casinos aunque, en rigor, no lo fuera. En otra línea, se sitúa el reciente trabajo de Germán Rueda, que traza una completa panorámica general sobre el fenómeno asociativo en la segunda mitad del siglo XIX, dedicando una singular atención a los casinos, aunque también se ocupa de otras formas asociativas ${ }^{20}$.

Partiendo de estos trabajos, y haciendo un uso debido de las fuentes orales y de toda la documentación generada por los casinos, se puede plantear un esquema metodológico que, considerando las circunstancias socioeconómicas del entorno, analice, a continuación, todos los aspectos relativos al casino estudiado. En este sentido, hay que averiguar su fundación y estatutos, trazar su composición social y analizar las condiciones de ingreso de los socios, su financiación y vida económica, sus objetivos: (recreo e instrucción), su vida interna - desde la renovación de sus juntas directivas y la participación de sus socios a sus empleados-, las posibles disputas políticas o religiosas y, por último, su proyección social, esto es, los contactos con otras entidades culturales, la organización de manifestaciones festivas o su comportamiento como grupo de presión ${ }^{21}$.

Tanto en las aportaciones de interés como en los trabajos menos reseñables, los propios casinos o las instituciones locales (ayuntamientos, diputaciones) y regionales han jugado un papel fundamental para que pudieran ver la luz. Como ocurre en otros temas, la celebración de centenarios es una buena excusa para publicar nuevas monografías sobre determinados casinos, aunque de desigual factura. Así, frente a los interesantes libros sobre los casinos de Ávila, San Sebastián, Tolosa o Sant Feliú de Guixols, aparecen otros de menor relieve, como el de la extremeña localidad de Don Benito.

El estudio sobre el casino abulense está organizado metodológicamente en cuatro períodos que enmarcan su evolución histórica con la coyuntura sociopolítica y cultural de la época; son destacables también su buena selección biblio-

Estudi General, Girona, 1, 1981, pp. 143-150; GUERENAA; Jean-Louis: «Una aproximación a la sociabilidad popular: el caso de Asturias bajo la Restauración (1875-1900)", Estudios de Historia Social, Madrid, no 50-51, 1989, pp 201-222; GuIMERÁ RAVINA, Agustín y Darías PrínCIPE, Alberto: El casino de Tenerife, op. cit.; BATALLA.I GALIMANY, Ramón: Els casinos republicans: política, cultura i esbarjo. El casino de Rubí, 1884-1939, Barcelona, Publicacions de l'Abadia de Montserrat (Biblioteca Serra d'Or), 1999, $316 \mathrm{p}$.

19 Temes Rodríguez, José Luis: El Círculo de bellas artes, Madrid, 1880-1936, Madrid, 2000.

20 RUEDA, Germán: "Formas de sociabilidad y cońdiciones de vida en la segunda mitad del siglo XIX», en SÁNCHEZ MANTERO, Rafael (Ed.): En torno al «98». España en el tránsito del siglo XIX al $X X$, Huelva, Universidad de Huelva, 2000, t. I, pp. 47-90.

21 Ver ZOZAYa MONTES, María: El Casino de Madrid, orígenes y primera andadura, Madrid, Casino de Madrid, 2002, 280 p.

Hispania, LXIII/2, núm. 214 (2003) 443-466 
gráfica organizada cronológicamente sobre los casinos, las biografías de sus presidentes y los apéndices (con sus estatutos y reglamentos primitivos, relaciones onomásticas, primeras actas, etc.) ${ }^{22}$. En cuanto al relativo a San Sebastián, la historia del casino viene a ser una especie de hilo argumental para trazar una crónica de Donostia en la época contemporánea (dada la trascendencia que supone para la vida urbana), y está acompañado de una interesante y abundante documentación gráfica y documental, no sólo de la vida social sino también de planos arquitectónicos ${ }^{23}$.

Por su parte, Ángel Jiménez completa en su artículo sobre el Casino dels Nois, cuyo origen está en el centenario del Casino de Sant Feliu de Guixols, la visión que había ofrecido Lluís Esteva Cruañas en sendos artículos anteriormente ${ }^{24}$. Con ellos contrasta el libro de Cabezas de Herrera Fernández acerca del Casino de Don Benito pues en él prevalece lo descriptivo y presenta además importantes lagunas temporales derivadas de la carencia de actas para determinados períodos 25 .

A veces, la publicación de monografías sobre casinos depende de otros factores menos dignos de celebración. Así, el incendio y destrucción de la documentación del Casino de Priego de Córdoba sirvieron como acicate para acelerar la publicación de una buena monografía, cuya investigación se había iniciado con anterioridad ${ }^{26}$.

Por otro lado, hay aproximaciones a la tipología o la evolución arquitectónica de determinados casinos, pues su localización, morfología y decoración se convierten en un dato fundamental del paisaje urbano y contribuyen al desempeño de su función ${ }^{27}$. De especial interés es la construcción del gran Casino de San Sebastián y de los casinos murciano, gaditano o madrileño, entre otros ${ }^{28}$.

Pero si agrupásemos geográficamente los estudios antes referidos, apreciaríamos grandes contrastes que deberían ir subsanándose. Por un lado, encon-

22 Fernández Hernández, Maximiliano: Casino abulense, op. cit.

23 SADA, Javier María y HeRnándeZ, Tomás: Historia de los casinos de San Sebastián, siglos XIX y XX: centenario de la construcción del gran casino de San Sebastián, 1887-1987, San Sebastián, 1987.

24 JIMÉNEZ, Ángel: «El casino dels Nois: cent anys de vida guixolença», Revista de Girona, Gerona, n 138, 1990, pp. 30-38; ESTEVA I CRUAÑAS, Lluís: «El Casino dels «Nois» de Sant Feliu de Guixols», Revista de Girona, Gerona, $n^{\circ} 85,1978$, pp. 345-356, y nº 87, 1979, pp. 61-71.

25 Cabezas de Herrera Fernández, María Dolores: Casino de don Benito: 100 años de bistoria, Don Benito, 1998.

26 AlCÁlÁ ORTIZ, Enrique: El casino de Priego, op. cit.

27 Una excelente aproximación al respecto - a la que remitimos por traspasar las fronteras del artículo que nos ocupa - la ofrece PéREZ ROJAS, Javier: Casinos de la región murciana, op. cit., pp. 26 y ss.

28 Además de ocupar la atención prioritaria del libro de PÉrez ROJAS, Javier: Casinos de la región murciana, el Casino de Murcia sirve de "pretexto" para tratar el tema de la arquitectura ecléctica en el libro de Vera Boti, Alfredo: El casino de Murcia, op. cit. Sobre los casos de Cádiz y de Madrid, ver Millán ChIVITE, José Luis y Pérez Mulet, Fernando: «Acerca del casino gaditano», Boletín del Museo de Cádiz, Cádiz, n 3, 1981-1982, pp. 113-117, y NAVASCuÉs PALACIO, Pedro: «El casino de Madrid y la arquitectura de su tiempo», en Tres conferencias de Arquitectura, Madrid, 1978. 
tramos el gran interés suscitado por los casinos murcianos, madrileños y el gaditano, o el exhaustivo conocimiento de algunas localidades catalanas - como Sant Feliu de Guixols o Llagostera-, así como el notable conocimiento de varios casinos asturianos, canarios, guipúzcoanos y castellanos; pero, la otra cara la vemos en el relativo vacío que, al respecto, ofrecen algunas comunidades autónomas como Aragón ${ }^{29}$, Baleares ${ }^{30}$, Cantabria, Castilla-La Mancha ${ }^{31}$, Galicia ${ }^{32}$, Navarra, La Rioja y la Comunidad Valenciana ${ }^{33}$.

\section{ORIGEN Y EVOLUCIÓN HISTÓRICA DE LOS CASINOS}

Un problema, a la luz del estado actual de las investigaciones, es la fijación de una cronología precisa en la evolución de la tendencia asociativa española, a partir de fuentes que puedan recoger un extenso número de asociaciones. Las estadísticas oficiales carecen de la continuidad precisa al respecto y fueron elaboradas con cambiantes criterios de clasificación ${ }^{34}$. Además, la metodología de los investigadores también ha sido dispar y requeriría de estudios más detallados que se fijaran en espacios geográficos delimitados para su mayor precisión ${ }^{35}$. Con todo, destacan algunos hitos y momentos clave en los que se ha impulsado, en general, el fenómeno asociativo y, en particular, el de tipo recreativo.

Si durante el primer tercio del XIX, las tensiones y crisis de la sociedad española así como las restrictivas normas impuestas por Fernando VII impidieron el florecimiento de este tipo de instituciones, la vuelta de los exiliados liberales supuso la importación de las modas de los ateneos, liceos, conservatorios o clubs ingleses ${ }^{36}$.

La relativa recuperación que supuso el período isabelino marcó una primera eclosión de los casinos españoles, asentándose en viejos palacios remodelados o

29 BlasCo IJAzO, José: Historia del Casino de Zaragoza (1843-1972), Zaragoza, Publicaciones de «La Cadiera», 245, 1972, 40 p.; VANHILle-Lité, Jean-Claude: Casinos y Círculos en Zaragoza (1830-1908), Zaragoza, Institución «Fernando el Católico», 2001, 283 p.

30 LEZCANO PASTOR, Alicia y Rosselló, $\mathbf{M}^{\mathrm{a}}$ Concepción: «Sociedades privadas mallorquinas del siglo XIX: introducción a su catalogación», Bulletí de la Societat Arqueològica Luliana, t. XXXIX, 1983, pp. 539-545.

31 SÁNCHEZ PICAZO, Miguel: «Entidades y asociaciones culturales y sociales en La Roda desde la Restauración a la guerra civil (1936-1939)», en Congreso de Historia de Albacete 8-11 de Diciembre de 1983. IV. Edad contemporánea, Albacete, Instituto de Estudios Albacetenses, 1984, pp. 529-551.

32 VeIGA, Baltasar: Círculo Mercantil de Vigo (1891-1971), Vigo, Gráf. Gestoso Bouzas, 1978.

33 Murria Arnau, C.: Casino antiguo de Castellón, Castellón de la Plana, 1991.

34 Ver el trabajo clásico de GuereÑA, Jean-Louis: «Fuentes para la historia de la sociabilidad en la España contemporánea», Estudios de Historia Social, Madrid, n 50-51, 1989, pp. 273-308.

35 Una propuesta interesante y centrada en un ámbito geográfico reducido, aunque requeriría de otros contrastes, la realiza SOLÁ, Pere: Itineraris per la sociabilitat meridional catalana. L'associacionisme i la cultura popular a la demarcació de Tarragona (1868-1964), Tarragona, Diputació de Tarragona, 1998.

36 Guimerá Ravina, Agustín y DaríAs PrínÇIPE, Alberto: El casino de Tenerife, op. cit., p. 35.

Hispania, LXIII/2, núm. 214 (2003) 443-466 
construyendo otros de nueva planta, adquiriendo ya la imagen de casino decimonónico ${ }^{37}$. Pero el control y la vigilancia gubernativos, que perseguía actividades políticas consideradas ilícitas así como juegos prohibidos, motivaron limitaciones constantes a la vida asociativa, que, no obstante, no impidieron su progresivo incremento ${ }^{38}$.

No es infrecuente que la fundación de los casinos arrancase a iniciativa de los integrantes de una tertulia constituida informalmente en los salones de un café. Así ocurrió, por ejemplo, con el Casino de Madrid, nacido en 1836 de un núcleo artístico y literario que se reunía en el ambiente romántico de los cafés del Príncipe y de Solito. Parece que la intención inicial de sus fundadores era huir de las azarosas discusiones políticas que se desarrollaban en dichos cafés ${ }^{39}$. Se opera, de esta manera, un salto cualitativo que liga ambas perspectivas de un mismo fenómeno social: la sociabilidad informal y la formal. Por supuesto, el hecho de su formalización no hace sino reforzar, asentar o instituir los vínculos que revestía con anterioridad la misma reunión de personas. Por otro lado, las razones que impulsan su creación también pueden estar relacionadas con el contexto económico de la ciudad, coincidiendo con un período de prosperidad económica o de recuperación, como sucede con los casinos fundados en Sant

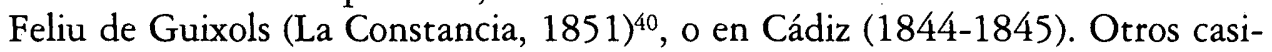
nos tempranos en España son los de Tenerife (1840), Gijón (1842), Murcia y Lorca (1847), Priego de Córdoba (1848) y León (1851) ${ }^{41}$.

La década de los sesenta supuso el impulso y crecimiento general de las sociedades de recreo, que se refleja en los distintos anuarios estadísticos, aunque concentrados especialmente en determinadas provincias como Baleares, Barcelona, Cádiz, Gerona, Guipúzcoa, Jaén, Logroño, Navarra, Sevilla y Zaragoza. Según las estimaciones de Germán Rueda, en 1861 existirán en España 575 casinos y sociedades de recreo. Gerona sería la provincia que más tendría (51), mientras que en Soria no funcionaba ninguno ${ }^{42}$.

El inicio de la Restauración marcó unas tendencias similares, con alrededor de mil seiscientas sociedades de recreo en España, más de la mitad del total de las censadas en España. En 1882, la encuesta del Ministerio de la Gobernación cifraba en 1.568 las sociedades de recreo y en 2.441 el total societario en España. En

37 PÉrez ROJAS, Javier: Casinos de la región murciana, op. cit., pp. 14-22.

38 Ver GuereÑA, Jean-Louis: «La sociabilidad en la España contemporánea», op. cit., pp. 30-31.

39 Así, al menos, lo ha recogido MonTERo Alonso, José: El casino de Madrid, op. cit., p. 8 y ss. Ver también, del mismo autor, Historia del casino de Madrid y su época, Madrid, 1995, y sobre todo ZOZAYA MONTES, María: El Casino de Madrid, op. cit.

40. Esteva i Cruañas, Lluís: «El Casino dels «Nois», op. cit., p. 345.

41 BOTREL, Jean-François: «La sociabilidad provinciana a mediados del siglo XIX: el Casino Leonés», en FUENTES, Juan Francisco y ROURA, Lluis (Eds.): Sociabilidad y liberalismo en la España del siglo XIX. Homenaje a Alberto Gil Novales, Lleida, Editorial Milenio, 2001, pp. 277-289.

42 RUEDA, Germán: «Formas de sociabilidad y condiciones de vida», op. cit., pp. 54-55. 
1887, poco antes de la ley de asociaciones, eran ya 1.658 de un total de $3.108^{43}$. Pero el impulso definitivo llegará con la ley de asociaciones del 30 de Junio de. 1887. En estos momentos, los casinos aparecen ya extendidos por toda España, excediendo el ámbito puramente urbano para llegar incluso a pequeñas localidades. Poblaciones como la asturiana Boal o la conquense Fuentes Claras (con escasos dos centenares de habitantes), contaban con un casino; y había municipios, como el tarraconense Bellmut, de apenas seiscientos, en el que funcionaban dos casinos a fines del siglo XIX (La Economía y La Constancia). Calculamos que había unos 1.968 casinos y círculos de toda clase en 1895. Andalucía era la región que más tenía (cuatrocientos veintidós) y Cantabria la que menos (sólo dieciséis) ${ }^{44}$.

El freno que la dictadura primorriverista causó a los casinos fue superado durante la $I^{\mathrm{a}}{ }^{\mathrm{a}}$ República, pues fueron unos años de revitalización de la vida social y, por ende, de dichas sociedades. Pero la guerra civil y el franquismo produjeron su desnaturalización. Para Pérez Rojas, «en la España de postguerra, el casino se desenvuelve con la misma monotonía e intrascendencia de las épocas caciquiles de finales del XIX y principios del XX, pero sin aquella competitividad y trasfondo político» ${ }^{45}$. Desaparecida cualquier posible discrepancia política, al ser controladas sus directivas por el Gobernador civil, su vida se centró en el fomento de los aspectos de recreo y, en algunos casos, se convirtieron en sociedades populares - renunciando a su pasado excluyente- promotoras de todo tipo de actividades ${ }^{46}$.

Durante la transición, los casinos provincianos sobrevivieron con el juego del bingo y la adaptación a los nuevos tiempos a través de ofertas como los clubes deportivos. Pero junto a ellos, el mundo de consumo y la legalización del juego impulsó los casinos de la costa.

\section{LA DIMENSIÓN LÚDICA}

Es evidente que la primera vocación de los casinos, como recogen sus estatutos, es la de satisfacer una demanda nueva, esto es, ocupar las horas de ocio de una determinada élite. Hay que entender por «tiempo de ocio» una categoría diferenciada de la de tiempo libre, pues aquélla debe vincularse a la sociedad contemporánea y surge entre la burguesía antes que entre las clases populares, dada la tardía regulación de la jornada laboral. Jorge Uría ha trazado con brillantez un recorrido crítico por la evolución del concepto en la moderna so-

\footnotetext{
${ }^{43}$ Ver GuEREÑA, Jean-Louis: «La sociabilidad en la España contemporánea», op. cit., p. 33, y «Fuentes para la historia de la sociabilidad», op. cit.

44 Datos de elaboración propia a partir del Anuario-Almanaque del Comercio, de la Industria, de la Magistratura y de la Administración, Madrid, Bailly-Baillère, 1895.

45 PÉrez ROJAS, Javier: Casinos de la región murciana, op. cit., p. 30.

46 Un caso típico lo representa el casino de Tolosa. Ver HOYO SIMÓN, José Félix del: Casino de Tolosa, op. cit., p. 25.
} 
ciología y el debate que, en torno a esta categoría, se ha suscitado desde diferentes frentes teóricos ${ }^{47}$. La ecuación ocio, sociabilidad formal y burguesía se hace realidad en el casino como ámbito idóneo para el desarrollo de una serie de prácticas culturales más o menos regladas. Es pues, una creación burguesa y a esta clase se vincularán la mayoría de los mismos durante largo tiempo, hasta que bajo el impulso, bien de fuerzas democráticas, bien de la Iglesia católica, se vayan constituyendo sus réplicas obreras o populares.

En este último sentido, como entidades vinculadas a las clases populares, encontraremos numerosos ejemplos en toda la península, especialmente estudiados para los casos catalán o asturiano en algunos trabajos modélicos de los que ya hablamos anteriormente ${ }^{48}$. De todos modos, pese a reproducir de alguna manera formas de sociabilidad burguesa, los ateneos y círculos obreros eran más activos y orientados a la educación popular o a la política, pasando a un segundo plano lo recreativo, además de diferir en relación al emplazamiento, la decoración, los ritos o las cuotas. Acerca de su denominación, Guereña considera que en estos casos se solía usar más el nombre de ateneo que el de casino, de acuerdo con su distinta orientación y procedencia ${ }^{49}$.

Ahora bien, aquí se abren varios debates. Por un lado, sería el encuadre de las casas del pueblo, que algunos autores consideran réplicas obreras del casino, mientras otros las califican de formas de sociabilidad específicamente popular ${ }^{50}$. La existencia de casinos y círculos con el apelativo de obrero o popular y orientados hacia las llamadas clases subalternas remiten a otro problema epistemológico de contornos no poco polémicos - el del debate que se puede establecer sobre la existencia de una verdadera "cultura popular» o su caracterización, por el contrario, como reflejo de la cultura de las élites-, que escapa de la finalidad de este artículo y, por tanto, baste sólo apuntarla y remarcar el carácter burgués de los casinos que aquí estamos tratando ${ }^{51}$.

\footnotetext{
47 Ver la Introducción de URía, Jorge: Una historia social del ocio. Asturias, 1898-1914, Madrid, Unión General de Trabajadores, 1996, en especial pp. 10-23.

48 Destaca al respecto el excelente libro de Batalla GaLimany, Ramón: Els casinos republicans, $o p$. cit., aunque el camino estaba abierto por el artículo de ESTEVA I CRUAÑAS, Lluís: «El Casino dels «Nois», op. cit. Para Asturias, ver GUEREŇA, Jean-Louis: «Una aproximación a la sociabilidad popular», op. cit., pp. 201-222. 36-39.

49 Ver GuEREÑA, Jean-Louis: «La sociabilidad en la España contemporánea», op. cit., pp. 203 y

so Sobre este tipo asociativo, puede verse el libro de LuIS MARTín, Francisco de y ARIAS GoNZÁLEZ, Luis: Las casas del pueblo socialistas en España (1900-1936): estudio social y arquitectónico, Barcelona, 1997, 238 p., José María Jover las considera la réplica obrera del casino de las clases altas o del ateneo de las clases mesocráticas y mercantiles en el clásico libro UBIETO, A., REGLÁ, J., JOVER, J. M. y SECO, C.: Introducción a la bistoria de España, Barcelona, 1974. De esta misma opinión participan, entre otros, PÉREZ ROJAS, Javier: Casinos de la región murciana, p. 31, así como GuIMERÁ RAVINA, Agustín y DARÍAS PRÍNCIPE, Alberto: El casino de Tenerife, op. cit., p. 23.

s1 Remitimos de nuevo a Jorge Uría. Además de la obra antes citada, puede verse su trabajo «La cultura popular y la historiografía española contemporánea: breve historia de un desencuentro»,
} 
Acerca de la manera de ocupar esas horas de ocio iban destinadas la mayor parte de las actividades que organizaba el casino o que podían desarrollarse en sus dependencias. La lectura era uno de los quehaceres cotidianos de los socios. Un claro ejemplo lo representa el Reglamento del Casino de Palma de Mallorca, que proponía cuatro medios para "proporcionar entretenimiento y diversión a sus suscriptores», a saber: "periódicos nacionales y extrangeros [sic] de todas clases y opiniones; y cuando los fondos lo permitiesen, obras escogidas, que se comprarán para la formación de una biblioteca selecta; juegos permitidos, y de moderado interés; conciertos; bailes» ${ }^{52}$. Los casinos no sólo se van a suscribir a diferentes periódicos y revistas, sino que, en la medida de sus posibilidades, van a ir formando bibliotecas que, en ocasiones, han llegado a albergar fondos importantes, como en el Casino de Murcia o el de Zaragoza ${ }^{53}$.

Pero más que entre libros o periódicos, la mayor parte del tiempo transcurría probablemente en torno a una mesa de juego: «Arriba, en el piso principal están las salas destinadas al juego, salpicadas de mesitas para el tresillo, poker y tute. Espléndidos salones, llenos a cualquier hora de oficiantes», escribía así sobre el Casino de Toledo Félix Urabayen ${ }^{54}$. El billar — que necesitaba una sala especial para albergar su mesa y, aunque improductivo, tenía una consideración social especial - el ajedrez, los naipes y el dominó fueron durante mucho tiempo los más practicados. La identificación actual del propio vocablo de casino con el juego y la apuesta no es casual, aunque haya variado mucho esta vertiente con el paso del tiempo.

De hecho, el juego constituía una de las formas de ingreso fundamentales de los casinos y les permitía mantener el esplendor de sus actividades e instalaciones o subsistir en épocas de crisis ${ }^{55}$. Si bien se pondrá especial empeño en aclarar expresamente en sus estatutos y reglamentos que se tratará de juegos permitidos por la ley, esta condición no siempre será observada con escrupulosa

\footnotetext{
en RUIZ, D., SÁNCHeZ, I. y ORTIZ, M. (Eds.): Movimientos sociales y estado en la España contemporánea, Cuenca, Universidad de Castilla-La Mancha, 2001. También se puede ver el breve pero sugerente debate que bajo el título «¿Qué es la historia de la cultura popular?» reproducía la revista Historia Social, Valencia, $\mathrm{n}^{\circ} 10,1999$, pp. 151-162. Algunas reflexiones de interés sobre la cuestión a partir de estudios más concretos en el tiempo y en el espacio, se encontrarán en BREY, Gérard: "Aproximación a la sociabilidad popular en las ciudades gallegas (1833-1914)», Estudios de Historia Social, Madrid, $\mathrm{n}^{\circ}$ 50-51, 1989, pp. 223-242; en la misma revista y número, MORALES, Manuel: «La sociabilidad popular en Málaga, 1840-1874: de la tutela burguesa a la afirmación de una identificación diferenciada», pp. 243-271; y, finalmente, la aportación de Solá, Pere: «Acerca del modelo asociativo de culturización popular de la Restauración» al colectivo editado por GUERENA, JeanLouis y TIANA FERrer, Alejandro: Clases populares, cultura, educación. Siglos XIX-XX, Madrid, Casa de Velázquez-U.N.E.D., 1989, pp. 393-402.

52 Reglamento del Casino de Palma de Mallorca, Palma de Mallorca, 1841, p. 3.

s3 Moralejo Álvarez, María Remedios y Pedraza Prades, María Dolores: La biblioteca del Casino de Zaragoza, Zaragoza, Institución «Fernando el Católico», 1982, 19 p.

54 URABAYEN, Félix: Toledo: Piedad, $2^{\mathrm{a}}$ ed., Madrid, 1925, p. 118.

ss Guimerá Ravina, Agustín y DaríAs PrínCIPE, Alberto: El casino de Tenerife, op. cit., pp. 77-78.
} 
severidad y en no pocas ocasiones los casinos se convertirán en verdaderos centros de apuestas, burlando el control gubernativo. El Gobernador de Ciudad Real publicaba así en el Boletín Oficial de la Provincia de Ciudad Real (9 de Setiembre de 1868) una carta-circular dirigida a los alcaldes de la provincia en la que recordaba la prohibición de las apuestas en los juegos de cartas de las que según dicho texto oficial participaban gente de toda clase social y eran practicadas en locales de todo tipo, incluyendo, desde luego, los casinos. En medio de la situación económica que se vivía como consecuencia de la crisis de subsistencia y, poco antes, de que estallara la "Gloriosa», se apelaba que en esos momentos el juego constituía una ofensa hacia los más desvalidos. Otra muestra de este tipo de prácticas clandestinas la podemos encontrar en el Casino de Tolosa, en donde se produjo un registro en 1920 a resultas de la denuncia de un socio por celebrarse con regularidad juegos clandestinos ${ }^{56}$. También en el Casino de Tenerife hay numerosas pruebas de juegos prohibidos ${ }^{57}$.

Algunos casinos regularían el incumplimiento de esta normativa sobre juegos u otras, como las relativas a la actividad política, contemplando la imposición de multas en lo que constituiría una especie de régimen disciplinario interno. Por ejemplo, el Casino de Aguilar del Río Alhama estipulaba en 1901 que, por infringir el primer artículo de su reglamento (relativo a la prohibición de juegos y a la discusión política o religiosa) se procedería al apercibimiento en primera instancia, o a multas de 10 y 25 pesetas en caso de una segunda o tercera reincidencia, y en caso de producirse un cuarto incumplimiento, se podría proceder a la expulsión ${ }^{58}$.

La cierta permisividad estatal (que aprovechaba la situación para convertir el juego en una fuente de ingresos hacendísticos) quedó quebrada en 1923, de manera que el prohibicionismo primorriverista supuso el fin de los cosmopolitas casinos de San Sebastián, que durante la belle époque, merced a la notable afluencia de público internacional, le habían proporcionado una vida boyante. Los edificios del gran casino de San Sebastián y el gran Kursaal marítimo fueron cerrados e incautados, perdiendo entonces la ciudad uno de los alicientes principales para veraneantes de cierto nivel económico procedentes de muy diversos lugares.

La importancia del juego desde el punto de vista financiero se correspondía con la fiesta - y su símbolo más evidente, el baile-, respecto a la esfera social. Era la otra cara de la moneda, pues generaba importantes gastos. De todos modos, el baile se convertía ocasionalmente en un verdadero acontecimiento social, repetido cíclicamente en significativas fechas como el carnaval o la nochevieja y que, incluso, contaba con regulación expresa en los estatutos. Así ocurre, por ejemplo, en el Casino Andaluz de Cádiz que, en su artículo 64 consignaba en 1872 que «esta sociedad celebrará todos los años un baile de disfra-

56 Hoyo Simón, José Félix del: Casino de Tolosa, op. cit., p. 12.

57 Guimerá Ravina, Agustín y Darías PrínCIPE, Alberto: El casino de Tenerife, op. cit., p. 80 y ss.

58 Reglamento del Casino de Aguilar del Río Albama, Logroño, 1901, p. 16. 
ces durante la época del carnaval, siendo deber de la junta directiva señalar el día en que deba efectuarse y las demás circunstancias a dar lucimiento y esplendor a la fiesta ${ }^{59}$. Algo parecido se contemplaba en el Casino de Guadalaja$\mathrm{ra}$, en cuyo caso se limitaba incluso el número de este tipo de actividades, pues «con cargo a los fondos de la sociedad. habrá sólo tres bailes al año, dos serán precisamente uno el día del corpus y otro en carnaval $»^{60}$.

A estos bailes acudían preferentemente los familiares de los socios y era la ocasión idónea para que la asociación diera acceso a un mayor número de personas. Era también una oportunidad única para que pudieran entrar las mujeres, a las que, durante décadas, sólo se les abría las puertas en las grandes fiestas, dado el carácter sexista de estas asociaciones. Valgan como muestra algunos ejemplos. En el Casino de Tenerife no se dio entrada a las mujeres hasta 1935 y la figura del socio femenino tenía restricciones en sus derechos. Y en el Casino abulense, las mujeres fueron admitidas como socias accidentales en los años cuarenta, restringiéndose a los casos en que eran cabezas de familia, y hasta los años ochenta no entraron en su directiva dos de ellas ${ }^{61}$. En efecto, hasta fechas recientes, los casinos españoles han contribuido al fortalecimiento de las relaciones de dominación androcéntrica y a la diferenciación social de papeles en función del género. $Y$ las mujeres encontrarán otros vehículos de asociacionismo y fomentarán sus relaciones en otros ámbitos de sociabilidad informal, al margen de este tipo de sociedades que les estaban vedadas ${ }^{62}$.

En suma, hay un componente festivo en todo ello, remarcado recientemente por Pere Solá en su estudio sobre la sociabilidad catalana y que remite, pues, a la repercusión exterior y a la socialización extensiva de lo que, en principio, es una asociación privada, limitada a un número de personas y restringida por una serie de normas, entre las que figuraba desde luego el pago de una cuota que habilitaba el acceso a sus instalaciones ${ }^{63}$. Este papel dinamizador de la vida lúdica en muchas localidades, rompiendo en parte su cotidianeidad monótona, les llevaba incluso a hacerse cargo de la organización de las fiestas mayores del pueblo. En este caso, estamos no ya ante una externalización del casino, sino ante su refor-

s9 Reglamento del Casino Andaluz, Cádiz, 1872, p. 18.

60 Reglamento orgánico del Casino de Guadalajara, Guadalajara, 1868, p. 4.

61 Ver Guimerá Ravina, Agustín y Darías PrínCiPe, Alberto: El casino de Tenerife, op. cit., pp. 47-48, y FERNÁNDEZ HERNÁNDEZ, Maximiliano: Casino abulense, op. cit., pp. 157-158.

62 Sin ánimo de exhaustividad — pues no es el objeto de estas páginas- se pueden recordar algunas aportaciones recientes al fenómeno asociativo comprendido desde la perspectiva de género como las siguientes, como NASH, M., PASCUA, M. J. y ESPIGADO, G. (Eds.): Pautas históricas de sociabilidad femenina: rituales y modelos de representación, Cádiz, 1999. Así mismo, ver RAMOS, M. D.: «Mujer, asociacionismo y sociabilidad en la coyuntura de 1898. Las afinidades con el fin de siglo europeo", en SÁNCHEZ, I. y VILleNA, R. (Eds.): Sociabilidad fin de siglo. Espacios asociativos en torno a 1898. Cuenca, 1999, pp. 73-99; y de la misma historiadora, «Identidad de género, feminismo y movimientos sociales en España», Historia Contemporánea, Bilbao, $\mathrm{n}^{\circ} 21,2000$, pp. 523-552.

63 SOLÁ, Pere: Itineraris per la sociabilitat meridional catalana, op. cit., p. 331 y ss. 
zamiento como agente social. Es el caso por ejemplo del Casino de Llagostera desde fines de los años veinte, y algo parecido podemos apreciar en Tolosa ${ }^{64}$.

No podemos olvidar, por otro lado, que, además de leer, jugar o danzar ocasionalmente, en los casinos también se bebía. La mayoría de ellos contaba con un bar entre sus dependencias y, algunos incluían un restaurante, como el Casino de Madrid, cuya carta era reconocida y apreciada en la capital ${ }^{65}$. La bebida como acto social nos remite al origen de muchas de estas asociaciones, como ya se ha indicado, y también al contraste con la taberna como espacio más propio de la sociabilidad popular, distinguiéndose así dos ámbitos para un mismo hábito del que participaban ambas clases sociales.

Junto al recreo, la instrucción aparece pronto como otra función complementaria, que, en ocasiones, podía desdibujar las fronteras entre casino y ateneo. Hay ejemplos, incluso, de unión de ambos conceptos, como ocurre en el Ateneo-casino obrero de Gijón ${ }^{66}$. Dicho de otra manera, los casinos no ignoran las actividades culturales a pesar de estar más orientados a las recreativas ${ }^{67}$. En este sentido, los responsables de los casinos no se conformarán con crear sus propias bibliotecas e iniciarán varias actividades culturales como conciertos, conferencias o concursos literarios que irán abriendo al resto de la población y, con ello, proyectando una determinada imagen del grupo que refuerza, a su vez, su posición de dominio desde el ámbito cultural. El diario cordobés Los Sucesos anunciaba así en Febrero de 1868 la convocatoria que el Círculo de la Amistad de Córdoba había promovido para la celebración de juegos florales. Los asuntos propuestos eran los siguientes: una oda a la Resurrección del Señor, un romance histórico en torno a D. Alfonso de Aguilar y una poesía descriptiva sobre la primavera en la sierra de Córdoba. Religión, historicismo y romanticismo tardío parecían, pues, dominar los gustos literarios de la junta rectora de dicha asociación ${ }^{68}$. Tales actividades significan otros vehículos para el impulso de las redes de solidaridad de clase que, obviamente, no sólo se tejen en el casino, mas también desde él.

$\mathrm{Y}$, por supuesto, ya fuera jugando, bebiendo u hojeando por encima algún periódico, en el casino, sobre todo, se charlaba, conversaba o discutía. Las tertulias venían a ser uno de sus reclamos fundamentales, convirtiéndose en un poderoso atractivo para sus socios y en una manifestación evidente de la ociosidad que se intentaba ocupar. R. Sánchez Madrigal definía así el Casino de Murcia en 1880 como "la tertulia que prospera, y no cabiendo ya en el reduci-

\footnotetext{
64 SolÀ, Pere: «El casino Llagonsterenç, de la primera dictadura a la guerra civil», Revista de Girona, Gerona, n 128, 1988, pp. 12-25; HoYo Simón; José Félix del: Casino de Tolosa, op. cit.

65 MONTERO, José: El casino de Madrid, op. cit., pp. 24-25.

66 GUEREÑA, Jean-Louis: «Una aproximación a la sociabilidad popular», op. cit., pp. 204 y 211-214.

67 Ver al respecto GUEREÑA, Jean-Louis: «La sociabilidad en la España contemporánea», op. cit., p. 32.

68 Los Sucesos, Córdoba, n 426, 21-II-1868.
} 
do espacio de una tienda ha invadido un verdadero palacio» ${ }^{69}$. Félix Urubayen comentaba por su parte, a propósito del Casino de Toledo, que «lo verdaderamente típico del casino son las tertulias, pues cada una de las taifas se descompone a su vez en media docena de corros. La principal es la del rincón, compuesta de procuradores y abogados. Da a luz casi todos los diputados provinciales. Su espuma política es la más brillante de la provincia» ${ }^{70}$. Y José Montero se refiere a las tertulias del Casino de Madrid como el «coro de los ángeles», nombre con el que era conocida la capital:

«Hay un aspecto en la vida del casino que inspira igualmente un interés: el de lo que allí se dice, con malicia ingeniosa... Es, singularmente, una temida tertulia la especializada en la visión burlona, irónica, maldicente de los hombres y las cosas... Forman el coro gentes de profesión muy diversa: desde un banquero a un escritor, desde un general a un médico... Y unidos todos en la malicia sonriente del comentario burlón, y en la frase de ingenio que luego Madrid en redacciones, cafés y saloncillos» ${ }^{71}$.

La conversación podía pasar por los últimos estrenos teatrales y novedades literarias entre los círculos más cultos, pero también por el más puro y simple chismorreo local, sin olvidar las discusiones políticas, que nos introducen ya en otra de sus dimensiones.

\section{OTRAS PERSPECTIVAS: LAS DIMENSIONES POLÍTICAS Y SOCIALES}

Por ahora, nos hemos fijado en las ofertas destinadas al esparcimiento de los socios del casino. Hasta la Ley de asociaciones de 1887, la discusión política estaba expresamente prohibida en los estatutos que regulaban su vida y así se hacía constar con frecuencia bajo fórmulas como la de que «se prohibe todo acto que tenga una tendencia política y toda controversia sobre puntos religiosos» ${ }^{72}$. José Montero asegura que el Casino de Madrid había nacido por la necesidad de un grupo de jóvenes para «vivir unas horas gratas, sin discordias, arrebatos ni rencores [logrando] un aislamiento gozoso» ${ }^{33}$.

Sin embargo, es evidente que, tanto antes como después de dicha ley, la política pasaba nécesariamente por sus salas, a veces mezclada con los intereses económicos. No podría ser de otra manera en el citado casino madrileño, pues entre sus socios figuraban políticos que, tarde o temprano, tendrán responsabilidades ministeriales o parlamentarias desde posiciones ideológicas tan distantes como Salamanca, Prim, Cánovas del Castillo o Sagasta. Otro claro ejemplo de

69 PÉRez RojAS, Javier: Casinos de la región murciana, op. cit., p. 35.

70 URUBAyen, Félix: Toledo, op. cit., pp. 119-120.

71 MONTERO, José: El casino de Madrid, op. cit., p. 17.

72 Así constaba en el Reglamento orgánico del casino de Guadalajara, op. cit., p. 3.

73 MonTero, José: El Casino de Madrid, op. cit., p. 9.

Hispania, LXIII/2, núm. 214 (2003) 443-466 
imbricación política lo representan los círculos hispano-ultramarinos, constituidos para la defensa de los intereses de la élite antillana pro-peninsular y el mantenimiento de la esclavitud en Cuba.

Lo habitual en las pequeñas localidades hasta bien avanzado el siglo XIX era que un mismo casino contara con socios de diferentes filiaciones políticas. Pero la convivencia no siempre resultó fácil entre ellos y cuando las tensiones se enconaban se llegaba a la escisión, tal como está documentado, por ejemplo, en Priego de Córdoba.

En el vibrante retrato que Félix Urabayen hizo del Casino toledano, se refería así a las dos «taifas» (los Silvias y los Zúñigas) en torno a las cuales se situaban los socios, y cuya división venía determinada más por el origen geográfico que por las opciones políticas, aunque añadía a continuación un comentario revelador:

«Tanto en los Silvias como en los Zúñigas hay toda clase de máscaras políticas: carlistas, liberales, reformistas, republicanos $[\ldots ..] \gg 74$.

Más adelante, Urabayen ejemplificará esta diversidad política con dos personajes, don Bernabé (que «milita en el campo tradicionalista») y don Juan Esquivias («radical avanzado [que] canta a todas horas los derechos del pueblo, la santa libertad de los ciudadanos» $)^{75}$.

Un ejemplo de confluencia de distintas opciones políticas podría ser el Casino de Tolosa, a donde acudían socios carlistas, liberales, republicanos y nacionalistas (minoritarios antes de la República), pero, por encima de todos, prevalecía el espíritu fuerista, que compartían también los republicanos y liberales, contrario al centralismo de Madrid. Por su parte, en Priego, las elecciones de 1882 fueron el desencadenante de una segregación consumada con la fundación de otra asociación rival del Casino, llamada "Círculo de Priego", rebautizándose el anterior como "Casino Primitivo". Aunque la escisión fue temporal, las divisiones entre «nicetistas» $\mathrm{y}$ «valverdistas» iban a ser constantes.

La libertad de asociación permitió el refuerzo de la vertiente política entre los casinos y afloraron los que añadieron su ideología a su denominación. Por aportar un dato estadístico - y dejando al margen los círculos católicos-, podemos decir que en 1895 existían en España al menos ciento sesenta y cuatro casinos o círculos con un calificativo claramente ideológico. Los había liberales (como el almeriense Círculo liberal de Vélez-Rubio), conservadores (como en la localidad albacetense de Villarrobledo), republicanos (como el de Ampuero, en Cantabria), fusionistas (el de Zaragoza), carlistas/tradicionalistas (como los de la conquense Tarancón o la vallisoletana Nava del Rey). Otros ejemplos podrían ser los siguientes: Círculo Liberal Dinástico de Cádiz, Casino de Aspiración Republicana de Mairena del Alcor (Sevilla), Casino Autonomista de Zaragoza, Círculo Progresista y de Unión de Valdepeñas (Ciudad Real), Casino

\footnotetext{
74 URABAYEN, Félix: Toledo, op. cit., p. 118.

75 Ibid., pp. 133-134.
} 
Republicano Zorrillista de Las Pedroñeras (Cuenca) o Casino Silvelista de Higuera La Real (Badajoz) ${ }^{76}$.

En una misma localidad podrá establecerse una dualidad de casinos o incluso más de dos. Así, por ejemplo, en Gijón había tres casinos diferentes durante la Restauración, con distinta composición social y posicionamiento políticos: el Casino (creado en 1842), el Círculo mercantil industrial (1873) y el Ateneocasino obrero $(1881)^{77}$.

Se especificara o no en su denominación, no será infrecuente que dicha dualidad correspondiera con los dos partidos dinásticos de la Restauración, como, por ejemplo, en Cádiz, donde coexistieron el Círculo liberal conservador con el liberal dinástico. Pero también podían corresponder a otras opciones que, con estar alejadas del poder, articulaban en estas asociaciones un vehículo de expresión y solidaridad interna. Sin tener que acudir a los casos de las grandes ciudades — donde era más factible la variedad - podemos traer a colación ejemplos como los de la pequeña localidad zaragozana de Fuentes de Jiloca (de apenas un millar de habitantes), en donde convivían los casinos católico tradicionalista y republicano federal; o la riojana Haro (con cerca de siete mil quinientos habitantes), en donde estaban representadas esas formaciones políticas, aglutinadas en torno al círculo republicano coalicionista y al casino carlista.

Se trataba, sin duda, de un síntoma de diversidad partidista y de la extensión, lenta pero progresiva, de la socialización política, así como — según ha señalado Germán Rueda - a un mayor grado de complejidad social que no necesariamente debía corresponder al crecimiento demográfico ${ }^{78}$. ¿Es prueba igualmente de las diferencias sociales? En menor medida, pues casinos liberales y conservadores seguirán estando integrados por miembros de una misma clase social de la que se nutren las clases caciquiles, a las que tampoco escaparán estos entramados asociativos.

Serán muchos los casinos que mantengan en sus estatutos el alejamiento de la política tras la entrada en vigor de la Ley de asociaciones, cuestión que, de todos modos, era más voluntariosa y formal que real. La revista Vida Manchega se refería en 1914 a la cuestión de manera crítica en los siguientes términos:

«Y a propósito de las elecciones. El mentidero del Congreso se ha trasladado estos días a los casinos provincianos. Los reglamentos de todos estos casinos, contienen un artículo que prohibe hablar de política, pero no obstante, no se habla

${ }^{76}$ Datos extraídos del vaciado que el G.E.A.S. hizo del Anuario-Almanaque de Bailly-Baillère, 1895. Sobre las posibilidades de dicha publicación como fuente de estudio del fenómeno asociativo contemporáneo en España, ver GEAS: España en sociedad, op. cit., pp. 21-28, y también ALÍA, F. y VILLENA, R.: "Asociacionismo y sociabilidad en Castilla-La Mancha: nuevas fuentes, nuevas aportaciones», en MAZA ZORRILLA, Elena: Sociabilidad en la España contemporánea: bistoriografía y problemas metodológicos, Valladolid, Universidad de Valladolid, 2002, pp. 77-101.

77 GUEREÑA, Jean-Louis: «Una aproximación a la sociabilidad popular», op. cit., pp. 201-222.

78 RUEDA, Germán: «Formas de sociabilidad y condiciones de vida», op. cit., p. 56. 
ahora en ellos de otra cosa. Con lo cual queda demostrado que los reglamentos de los casinos no sirven para nada. Y que las juntas directivas y el personal a sus órdenes no son mejores ni peores que los ministros responsables y las autoridades subalternas» 79 .

Pero lo que la prensa comentaba como hábito frecuente en la mayoría de los casinos, aunque encubierto bajo la apariencia formal de apartidismo, se convirtió en algunos casos en una finalidad expresa, articulándose entonces una clara ligazón entre «casino» y "partido», de suerte tal que el primero era una prolongación del segundo, aunque respondiera a un formato asociativo y nominal diferenciado. Encontramos un ejemplo representativo de este proceso de disolución de fronteras funcionales en el Reglamento del Casino liberal gaditano de instrucción en 1908. El artículo segundo rezaba que su objeto era "difundir y propagar las doctrinas liberales y democráticas, a la vez que estrechar los vínculos de unión y solidaridad entre sus correligionarios", para lo que proponía la organización de veladas, conferencias y cualquier otro medio que incrementara la propaganda liberal en la ciudad, así como la creación de dos centros subsidiarios, ubicados en sendos barrios. El nexo con el partido liberal en Cádiz era claro: «El comité local del partido podrá celebrar en los salones del casino sus juntas y cuantos más actos políticos necesite realizar» ${ }^{80}$.

Los ejemplos de casinos vinculados a opciones políticas no dinásticas cobran un singular valor. Los casinos carlistas - que se habían multiplicado en los años sesenta y habían sido cerrados en varios casos durante el Sexenio revolucionario- fueron un elemento esencial para la supervivencia de un ideario en declive desde la Restauración que, no obstante, desplegó una serie de estrategias de supervivencia y cohesión interna, entre las que el círculo o el casino ocupaba un papel destacado para la permanencia del grupo político. En palabras de un buen conocedor de este movimiento político como Jordi Canal, llegaron a significar «la base de la reestructuración carlista de los últimos años del ochocientos [y] el punto de referencia ineludible de los principales líderes carlistas en sus discursos» ${ }^{81}$.

Distinto fue el papel de los casinos republicanos. Más próximos a una suerte de mesocracia local y con vocación de abrir sus puertas a las clases popula-

79 Vida Manchega, Ciudad Real, $n^{\circ} 20,26-$ II-1914.

80 Reglamento del Casino liberal gaditano de instrucción, Cádiz, 1908, pp. 3, 4, 7 y 12.

81 CANAL, Jordi: «Espacio propio, espacio público. La sociabilidad carlista en la España mediterránea en la etapa de entresiglos", en SÁNCHEZ, I. y VILLENA, R.: Sociabilidad fin de siglo, op. cit., p. 131. Ver del mismo autor «Dal circolo alla piazza. La sociabilità política legittimista nella Spagna mediterranea tra Otto e Novecento", en Memoria e Ricerca, Rivista di Storia contemporanea, $\mathrm{n}^{\circ} 5$, 1995, pp. 47-64, y también ENRíQUEZ DEL ÁRBOL, Eduardo: «Notas para una historia de las ideologías en la España del siglo XIX: el partido carlista en un cotidiano católico de 1870", Anuario de Historia Moderna y Contemporánea, Granada, n²10, 1983, pp. 113-152. 
res $^{82}$, parece claro que también partieron de iniciativas gestadas entre la mediana y pequeña burguesía local. Antes de que la libertad de asociación fuera un hecho, sus instalaciones sirvieron para fomentar el crecimiento de esta tendencia política y, con posterioridad, su conexión con el comité de la respectiva localidad se mantuvo, incrementando su activismo en períodos electorales ${ }^{83}$.

Durante el franquismo, la vinculación entre política y casino siguió un camino diferente al observado hasta ese momento, como se ha documentado en Ávila ${ }^{84}$. Si anteriormente había sido frecuente que ex políticos formaran parte de sus directivas, el control que sobre las mismas ejercerá ahora la autoridad gubernativa, provocará que el casino sirviera de plataforma para pasar a ocupar concejalías o puestos en las diputaciones.

Pero los casinos tenían también una proyección social, pues la iniciativa privada debía llenar hasta bien entrado el siglo XX el vacío que dejaba el Estado al respecto. Aunque en varias trabajos sobre los casinos se hace alusión a sus campañas filantrópicas, un caso excepcional en cuanto al filantropismo lo representa el casino gaditano, de tal suerte que ha dado lugar a una monografía sobre el tema, justificada en parte por su posición geográfica. Así, en la segunda mitad del siglo XIX reunió una suma considerable para hacer frente a la epidemias de cólera-morbo de 1854 y de 1885 , promovió la creación de un hospital de sangre con motivo de la repatriación de los militares vencedores de la guerra de África (1859) y costeó el ingreso de los derrotados militares venidos de Cuba (1898) en el hospital de San Juan de Dios ${ }^{85}$.

Ante la falta de servicios asistenciales, la burguesía utilizaba pues los casinos para mostrar su «sensibilidad» a la miseria ajena, sobre todo en épocas de epidemias, guerras o desastres naturales. Cada casino destinaba un porcentaje de su presupuesto a beneficencia. Un casino como el de Tenerife tenía así comprometidos una serie de donativos a distintas instituciones en el primer tercio del siglo XX, como el hospital de niños, la Cruz Roja, el asilo Victoria, etc., y colaboraba en momentos excepcionales como las catástrofes de La Gomera en

82 SoLÀ, Pere: «El casino Llagonsterenç», op. cit., pp. 12-25, habla de una institución esencialmente mesocrática identificada con el proyecto populista de Esquerra Republicana de Catalunya. En esta misma línea, pero mucho más desarrollada es la tesis defendida en el libro de BATALLA GALIMANY, Ramón: Els casins republicans, op. cit.

83 Una aproximación a su funcionamiento y papel puede seguirse a través del caso malagueño, bien estudiado por MORALEs MUÑOZ, Manuel: El republicanismo malagueño en el siglo XIX. Propaganda doctrinal, prácticas políticas y formas de sociabilidad, Málaga, 1999, pp. 164-187. Por otra parte, la importancia de las formas asociativas pre-políticas para la difusión del ideario republicano ya fue subrayada por los estudiosos de este movimiento político. Ver, por ejemplo, JUTGLAR, Antoni: Pi i Margall y el federalismo español, Madrid, Taurus, 1975, t. I, pp. 438-440, y, para los círculos políticos en general, RUEDA, Germán: «Formas de sociabilidad y condiciones de vida», op. cit., pp. 60-63.

84 FERnÁNDEZ HeRnándeZ, Maximiliano: Casino abulense, op. cit., p. 163.

85 Nogueroles Alonso De LA SierRA, Pedro J. y otros: El casino gaditano ante las crisis sanitarias del Cádiz decimonónico, Cádiz, 1999.

Hispania, LXIII/2, núm. 214 (2003) 443-466 
1911, así como en las llamadas «cocinas económicas» durante la $\mathrm{I}^{\mathrm{a}}$ Guerra Mundial. Estas atenciones las hacía extensivas a su propio personal ${ }^{86}$.

Ahora bien, esta "preocupación social» no estará exenta de un cierto grado de hipocresía en algunas iniciativas. $\mathrm{Y}$ en los casos en que su compromiso fue más sincero y sobrepasó la mera «caridad» tendió a durar poco por el costo económico que suponía. Según José Antonio Martín de Marco, tanto el Casino de Numancia como el Círculo de la amistad de Soria, pese a su precariedad económica, «fueron muy sensibles a las necesidades de la sociedad soriana, y lo mismo invitan a tomar café, licor y un cigarro a la clase de tropa y oficialidad que partía a la guerra de Cuba, que compran bonos de cocina económica para repartir entre la clase menesterosa de la ciudad» ${ }^{87}$. Por su parte, el Casino de Tolosa, además de realizar campañas de ayuda a los damnificados de las inundaciones de Elizondo en 1907 y a los familiares de las víctimas del Riff en 1901 , se implicó en un proyecto de mayor calado, como la fundación de una colonia escolar en 1917 que acabó por disolverse en 1925 tras la protesta de algunos socios ante la «excesiva responsabilidad» asumida por el casino ${ }^{88}$.

\section{ORGANIZACIÓN INTERNA}

Como lugares privados que eran, sólo los socios del Casino tenían acceso. El pago de unas cuotas era no sólo fundamental para su mantenimiento sino, a la vez, un medio de exclusión social. Para llegar a formar parte de ese selecto club había que solicitarlo de forma reglamentaria y resultar admitido por votación. Su carácter restrictivo explica su apariencia esplendorosa, convirtiéndose el lujo de los casinos en una especie de exigencia para la reunión y el distanciamiento de la clase privilegiada ${ }^{89}$.

Conforme fueron extendiéndose los casinos por la geografía española, el número de socios fue aumentando, aunque es difícil ofrecer un dato o una media estadística al respecto. Generalmente, se distinguían varias categorías con denominaciones distintas, que en los casos más elaborados llegaban a cuatro: «de número», «fundadores», «de honor» y «transeúntes»; éstos últimos —admitidos de forma provisional cuando algún empleado público o comercial debía residir en la ciudad por motivos laborales - no gozaban del derecho a voto en las asambleas. También oscilaba la edad para acceder a tal condición, aunque, en cambio, lo que sí parece ser constante es la necesidad de que el nuevo candidato hubiera de ser presentado por otro socio o por varios de ellos. Al Casino de Chinchón se podía acceder a la edad de 18 años, mientras que en el de Lleida se requería ser

86 Guimerá Ravina, Agustín y Darías PrínCiPe, Alberto: El casino de Tenerife, op. cit., p. 100 y ss.

87 MARTín DE MARCO, José Antonio: El casino y el círculo de la amistad-numancia, op. cit., prólogo.

88 Hoyo Simón, José Félix del: Casino de Tolosa, op. cit., p. 14 y ss.

89 DíAZ PlAJA, Guillermo: «España en sus espejos. Los casinos», op.cit., pp. 22-23. 
mayor de edad. En los casinos de Benimaclet y Cesures, no sólo se especificaba una edad mínima (18 y 23 años respectivamente), sino también observar una «buena conducta» en general o una «buena conducta moral y política», demostrando así una tendencia de control social elitista por parte de estas asociaciones ${ }^{90}$.

El aumento de socios motivó la búsqueda de nuevos locales adecuados para sus actividades por parte de sus juntas directivas, pues en sus inicios se ubicaban en pequeñas casas de alquiler o en plantas superiores de las mismas. El ejemplo de Madrid puede ser bien ilustrativo de la significación que llegará a alcanzar el edificio del casino ${ }^{91}$. Pero no sólo en las grandes ciudades se pretendía encontrar un mejor y más bello emplazamiento para la asociación. Así, ha sido posible que con el paso del tiempo, varios casinos de ciudades medianas (como Murcia y Almería ${ }^{92}$ ) o de poblaciones que no eran capitales de provincia (Tolosa o Manresa, por ejemplo93) hayan sido declarados monumentos histórico-artísticos. En suma, el edificio se convierte en un elemento simbólico de la ciudad y de pequeños municipios, donde el casino se ubica en sus plazas mayores o calles principales. Pasa, por tanto, a integrarse en la iconografía urbana de una burguesía en ascenso o plenamente consolidada.

¿Cómo se organizaban internamente los casinos? En líneas generales, todo casino tenía como órgano rector una junta directiva compuesta al menos por un presidente y un secretario, a los que se sumaban normalmente los cargos de tesorero, vicepresidente y algunos vocales. Sus funciones se contemplaban en los reglamentos, que asimismo preveían las cuotas que debían abonarse tanto para el ingreso como en concepto de mensualidad o anualidad, según los casos. Las cuotas variaban en función de los casinos y su adscripción social. La casuística al respecto es muy variada, pero en todos los casos, se buscaba no sólo la exclusión de las clases menos pudientes (en el caso de los llamados «casinos de señoritos»), sino también la propia diferenciación en función de su consideración de fundador, transeúnte, etc. De los gastos e ingresos, los responsables de los casinos debían dar cuenta a la autoridad gubernativa, tal y como contemplaba la Ley de asociaciones, que sometía así a los casinos a un control importante. Por otra parte, no puede decirse que fueran vivos ejemplos de democra-

90 Reglamentos del Casino principal de Lleida (1924), del Casino «La Iberia» de Chinchón (1912), del Casino instructivo y benéfico de Benimaclet (1898), y del Casino de Cesures (1908).

91 Ver al respecto MONTERo AlONSO, José: El casino de Madrid, op. cit., así como el informe histórico sobre rehabilitación del edificio en Casino de Madrid, Madrid, n 142, 1991, pp. 20-32.

92 Respecto al edificio del casino murciano, ver Vera BOTI, Alfredo: El casino de Murcia, op. cit., y GUIRAo LÓPEZ, J.: El casino de Murcia, op. cit., pp. 15 y 19, quien lo califica como el edificio civil más importante construido en Murcia por iniciativa privada y declarado monumento históricoartístico nacional por R. D. 527/1983 de 16-II-1983. Para el Casino de Almería, ver CHuECA GoITIA, Fernando: "Casino cultural de Almería», Boletín de la Real Academia de la Historia, Madrid, vol. $181, \mathrm{n}^{\circ} 1,1984$, pp. 122-123.

93 Respectivamente, Hoyo Simón, J. F.: Casino de Tolosa, op. cit., pp. 7-10, y CHUECA GoITIA, Fernando: «Casino de Manresa (Barcelona): declaración de monumento histórico artístico», Boletín de la Real Academia de la Historia, Madrid, vol. 177, n³ 1980, pp. 617-662.

Hispania, LXIII/2, núm. 214 (2003) 443-466 
cia interna. Las críticas no siempre eran bien recibidas y ello podía degenerar en serios conflictos en su seno. Un ejemplo se vivió así en Llagostera en 1929 cuando la Junta directiva se negó a discutir en asamblea la petición de reforma formulada por un grupo de socios que constituían la oposición interna ${ }^{94}$.

En cuanto a los asuntos económicos, la lectura de los trabajos publicados sobre los diversos casinos repartidos por la geografía española denota que no eran empresas demasiado saneadas. Sus inicios solían ir de la mano de una precariedad económica que el ingreso de nuevos socios paliaba en principio. Sin embargo, este progresivo crecimiento empujaba más tarde a la adquisición de un nuevo edificio, generándose de esta manera un endeudamiento a largo plazo que en las coyunturas más críticas (tras las guerras mundiales o la civil, singularmente) conducían a la penuria económica de la institución o incluso su desaparición.

Para evitar tal extremo, se fueron articulando algunas soluciones no siempre solventes, como el incremento de las cuotas (idea que era desechada en la mayoría de los casos por ahuyentar los nuevos ingresos y provocar bajas), la constitución de sociedades, la emisión de obligaciones, o, más recientemente, la búsqueda de nuevas formas de ingreso (como el bingo).

El casino constituye pues un elemento clave de la sociabilidad burguesa. «El Casino es tan indispensable a aquella capital que si llegara a desaparecer, la creación de otro círculo análogo se impondría muy rápidamente» constataba con orgullo el presidente del Casino de Oviedo en 189795 . Las estadísticas disponibles, bien para la monarquía isabelina, bien para la Restauración, nos muestran la importancia así como la multifuncionalidad de estos espacios de sociabilidad. "Las sociedades de recreo aumentan de día en día sobre todo en las pequeñas localidades», señalaban así los delegados españoles al Congreso internacional de estadística de La Haya en Septiembre de 1869, apuntando además que se trataba de «un hecho que entre otros denota el cambio favorable en las costumbres de nuestras poblaciones, pues la mayor parte de estas asociaciones no sólo ofrecen a sus miembros esparcimientos honestos, sino además los medios de instruirse, ya que poseen bibliotecas y algunas cuentan incluso con colecciones literarias y científicas» ${ }^{96}$. 18-19.

94 SOLÁ, Pere: «El casino Llagosterenc, de la primera Dictadura a la guerra civil», op. cit., pp.

95 Casino de Oviedo: Memoria presentada por la Junta directiva a la general celebrada el día ... de Mayo de 1897, Oviedo, Imprenta de Pardo, Gusano y Campo, 1897, p. 4.

96 Herreros De TeJADA, Feliciano y BALAgUer, Víctor: «Travaux statistiques des différents états.-Espagne", Congrès international de statistique à la Haye. Septième session du 6 au 11 septembre 1869. Troisième partie, La Haye, M. Nijhoff, 1871, pp. 22-23, cit. por GUEREÑA, Jean-Louis: «El «espíritu de asociación». Nuevos espacios y formas de sociabilidad en la España decimonónica», en FUENTES, Juan Francisco y ROURA I AULINAS, Lluís (Eds.): Sociabilidad y liberalismo en la España del siglo XIX, op. cit., p. 230. 